\section{(6) OPEN ACCESS}

\title{
Tobacco policy reform and population-wide antismoking activities in Australia: the impact on smoking during pregnancy
}

\author{
Alys Havard, ${ }^{1}$ Duong T Tran, ${ }^{1}$ Anna Kemp-Casey, ${ }^{2}$ Kristjana Einarsdóttir, ${ }^{3}$ \\ David B Preen, ${ }^{2}$ Louisa R Jorm ${ }^{1}$
}

${ }^{1}$ Centre for Big Data Research in Health, School of Population and Global Health, UNSW Sydney, Sydney, Australia ${ }^{2}$ Centre for Health Services Research, University of Western Australia, Perth, Australia ${ }^{3}$ Centre of Public Health Sciences and Unit for Nutrition Research, University of Iceland Reykjavik, Iceland

\section{Correspondence to}

Alys Havard, Centre for Big Data Research in Health, University of New South Wales, Level 1 AGSM Building, UNSW Sydney, NSW 2052, Australia;

alys.havard@unsw.edu.au

Received 20 February 2017 Revised 11 July 2017

Accepted 11 July 2017 Published Online First 4 August 2017
ABSTRACT

Introduction This study examined the impact of antismoking activities targeting the general population and an advertising campaign targeting smoking during pregnancy on the prevalence of smoking during pregnancy in New South Wales (NSW), Australia. Methods Monthly prevalence of smoking during pregnancy was calculated using linked health records for all pregnancies resulting in a birth $(800619)$ in NSW from 2003 to 2011. Segmented regression of interrupted time series data assessed the effects of the extension of the ban on smoking in enclosed public places to include licensed premises (evaluated in combination with the mandating of graphic warnings on cigarette packs), television advertisements targeting smoking in the general population, print and online magazine advertisements targeting smoking during pregnancy and increased tobacco tax. Analyses were conducted for all pregnancies, and for the population stratified by maternal age, parity and socioeconomic status. Further analyses adjusted for the effect of the Baby Bonus maternity payment.

Results Prevalence of smoking during pregnancy decreased from 2003 to 2011 overall (0.39\% per month), and for all strata examined. For pregnancies overall, none of the evaluated initiatives was associated with a change in the trend of smoking during pregnancy. Significant changes associated with increased tobacco tax and the extension of the smoking ban (in combination with graphic warnings) were found in some strata.

Conclusions The declining prevalence of smoking during pregnancy between 2003 and 2011, while encouraging, does not appear to be directly related to general population antismoking activities or a pregnancy-specific campaign undertaken in this period.

\section{INTRODUCTION}

In Australia, the proportion of women who smoke during pregnancy has declined $(11 \%$ in 2014, down from $17.3 \%$ in 2003). ${ }^{12}$ What is driving this decline has not been empirically determined. To our knowledge, the only population-wide programme targeting smoking during pregnancy was an advertising campaign with limited reach. ${ }^{3}{ }^{4}$ It has been suggested that the national decline in smoking during pregnancy occurred in response to strong antismoking efforts targeting the general population $^{5}$; however, no empirical evidence exists to support these claims.
World-leading population-wide programmes and policies have been implemented in Australia since 2003. These include mass media, plain packaging of tobacco products, graphic health warnings on cigarette packaging, increased tobacco taxes and the extension of the ban of smoking in enclosed public places to include licensed premises. Both mass media and rising cigarette cost were effective in reducing the prevalence of smoking in Australia's general population. ${ }^{6-9}$ Adding graphic warnings to cigarette packages was not associated with reduced smoking prevalence in Australia, ${ }^{8}$ but it was associated with increased calls to the smoking cessation helpline, as was the mandating of plain packaging. ${ }^{10}$ Evidence regarding the population impact of extending indoor smoking bans to include licensed premises is restricted to the Netherlands, where it was associated with increased quit attempts, but not reduced smoking prevalence. ${ }^{11}$

While there has been little evaluation of the impact of most of these initiatives on maternal smoking, the effect of increased taxes has been the focus of numerous studies, with fewer women smoking during pregnancy and more women quitting during pregnancy following tax increases. ${ }^{12-18}$ In much of this research, however, the potential impact of other population-wide programmes operating at the same time was not taken into account. A recent exception found both increased taxes and graphic package warnings in Uruguay to be independently associated with increased quitting during pregnancy. ${ }^{15}$ Similarly, after controlling for other population-wide programmes operating between 2000 and 2005 in 30 states in America, higher cigarette cost was associated with greater probability of quitting during pregnancy. ${ }^{12}$

To date, the impact of Australian population-wide activities on smoking during pregnancy has not been examined. This information is important for guiding decisions about future whole-of-population activities that are capable of reaching women who will go on to become pregnant. This study assessed the effect of population-wide antismoking measures on the prevalence of smoking during pregnancy in New South Wales (NSW), Australia's most populous state. This study also determined whether differences in the effect of these activities existed according to maternal age, parity and socioeconomic status (SES), given that previous studies have found variation in maternal responsiveness to antismoking initiatives. ${ }^{12-141618}$ 


\section{METHODS}

\section{Data sources and linkage}

The study population was identified from the NSW Perinatal Data Collection (PDC) linked to maternal hospital admission records from the NSW Admitted Patient Data Collection (APDC). The PDC is a legislated and whole-population surveillance system covering all births (live and stillbirths of at least 20 weeks gestation or $\geq 400 \mathrm{~g}$ birth weight) in NSW. The PDC contains information on the health of mothers and babies, including maternal sociodemographic characteristics and smoking status, collected at the time of birth. The APDC is a statutory data collection of all discharges from all public, private and repatriation hospitals, and private day procedure centres in NSW.

The linkage was performed by the Centre for Health Record Linkage, which has high linkage rates and demonstrated validity. ${ }^{19} 20$ All PDC records relating to births with conception dates between 1 January 2003 and 31 December 2011 were used, along with hospital separation records relating to the delivery. Pregnancies belonging to the same woman at different times during the study period were treated independently.

\section{Measurement of smoking during pregnancy}

For births from 2003 to 2010, PDC records contained items regarding smoking tobacco at any time during pregnancy and the number of cigarettes smoked per day after 20 weeks of pregnancy. From 1 January 2011, these items were revised to include smoking at any time during the first 20 weeks of pregnancy, smoking any time after 20 weeks of pregnancy until birth and number of cigarettes smoked per day in the first 20 weeks of pregnancy and number of cigarettes smoked per day after 20 weeks of pregnancy. Smoking during pregnancy was identified from positive responses to any of these PDC items or if a current tobacco use diagnosis was present in any diagnosis field of the APDC delivery record. ${ }^{21}$ The prevalence of smoking during pregnancy for each month in the study period was calculated as the number of women identified as smoking during pregnancy as a proportion of all pregnancies conceived in that month. Date of conception was calculated as date of delivery-(completed weeks of gestationx 7$)+14$ days. $^{22}$

\section{Measurement of antismoking policies and programmes}

Exposure to antismoking television advertisements was measured using Target Audience Rating Points (TARPs) for adults aged 18 years and older, obtained from a report prepared by OzTAM Pty for the Cancer Institute NSW. TARPs represent the percentage of the target audience exposed to an advertisement together with the average number of times a member of the target audience is exposed, adjusted for the length of the advertisement. Exposure to advertisements broadcast in NSW on free-to-air and cable television between April 2005 and December 2011 was measured with television monitoring devices and self-completed viewing diaries. For this study, exposure was calculated as cumulative TARPs over the previous 3 months, based on evidence regarding the duration of antismoking advertising exposure associated with increased quit attempts in the general Australian population. ${ }^{23} 24$ As data on exposure to antismoking television advertising in NSW prior to April 2005 were not available, a TARP value of 0 was assigned.

Smoking in all enclosed public places except licensed premises was banned in NSW in 2000. This ban was extended to include enclosed licensed pubs, clubs, nightclubs and casinos in 2007, after being phased in from 2005. The phase-in period involved banning smoking in 50\% of the enclosed area in July 2005, 75\% of the enclosed area in July 2006 and a total ban in July $2007 .^{25}$ In March 2006, graphic health warnings that covered 30\% of the front and $90 \%$ of the back of cigarette packs were mandated. In April 2010, a 25\% increase in tobacco excise and customs duty on tobacco products was implemented. Two antismoking advertisements targeting pregnant women and women of childbearing age were run in print and online magazines for 7 weeks from May $2011 .^{26}$

\section{Statistical analysis}

Segmented Poisson regression models were built to jointly examine the impact of each antismoking initiative on prevalence rates of smoking during pregnancy. ${ }^{27}$ The Poisson family function was substituted with the negative binomial method with a log-link function as this method accounts for overdispersion and autocorrelation. ${ }^{28} 29$

TARPs were entered as a continuous variable. Other policies were represented by trend indicator terms, which allow for the changes in the slope of the time series to be estimated. They take a value of 0 for each month prior to the introduction, and all following months are assigned consecutive numbers from 1 onward. ${ }^{30}$ Although it is also possible to test for changes in the level of a time series, ${ }^{31}$ immediate changes in the prevalence of smoking following the introduction of policies were not expected. Rather, if the policies were successful in encouraging women to quit smoking before becoming pregnant, this would manifest as a gradual decline in the smoking prevalence (ie, a change in the trend) given there is variation in the time it takes to quit smoking and the time it takes to conceive.

There were insufficient time periods between policies to independently estimate the impact of the $50 \%$ ban, graphic warnings and the extension of the smoking ban to $75 \%$ of the enclosed area. ${ }^{31}$ Hence, graphic warnings and the $75 \%$ ban were not included in the model and any observed changes in the trend from July 2005 to July 2007 were interpreted as the combined impact of these three policies.

It was anticipated that the change in PDC smoking questions in January 2011 may have increased the ascertainment of smoking during pregnancy. As the new smoking items were effectively introduced over a 4-month period, with births in January 2011 corresponding to conceptions in March to June 2010, any change in smoking ascertainment was expected to manifest in a change in the trend of smoking during the implementation period. So as not to falsely attribute any increase in smoking during this time to the antismoking initiatives represented by trend terms, these 4 months were censored in all models. Although censoring these months means that measurement of the post-tax increase trend in smoking did not commence until July 2010, the absence of data for the two time points immediately following the tax increase was not expected to influence the measurement of the trend given that the prevalence of smoking is a slowchanging outcome. Censoring these time points, however, does not remove the potential confounding effect of the change in smoking measurement on the relationship between TARPs and smoking prevalence. Whether such confounding was likely to be present was investigated with a sensitivity analysis in which TARPs and the underlying time trend were modelled for 2003 to February 2010, and separately for the period of July 2010 to December 2011. As the relationship between TARPs and smoking prevalence differed very little between these two time periods, potential confounding by the change in the measurement of smoking during pregnancy was not considered a major threat to the validity of the analyses. 
Analyses were conducted for all pregnancies $(\mathrm{n}=800619)$ and stratified by maternal age ( $<30$ and $\geq 30$ years), parity (primiparous and multiparous) and SES. Socioeconomic Indexes for Areas, Index of Relative Socioeconomic Disadvantage (IRSD) scores were mapped to statistical local area of residence. Births in 2003 to 2007 were assigned 2003 IRSD scores ${ }^{32}$ and births from 2008 to 2011 were assigned 2008 IRSD scores. ${ }^{33}$ The IRSD scores were grouped as disadvantaged SES (deciles 1-3), average SES (deciles 4-7) and advantaged SES (deciles 8-10).

The first round of models included a term for time only, in order to estimate the trend of smoking during pregnancy over the entire study period. The partially adjusted models included a time term and terms representing all the antismoking activities, entered simultaneously. In the fully adjusted models, a trend term representing the introduction of the Baby Bonus (maternity payment of 3000 Australian dollars for the birth of a child) in July 2004 was added. This policy changed the composition of the population giving birth in NSW, ${ }^{34}$ which could confound the relationship between the antismoking activities and the smoking trend.

All analyses were performed in SAS V.9.3. ${ }^{35}$ Ethical approval for this study was granted by the NSW Population and Health Services Research Ethics Committee.

\section{RESULTS}

\section{Prevalence of smoking during pregnancy}

This study included 800619 pregnancies among 534513 women. The mean prevalence of smoking during pregnancy was $13.8 \%$. The prevalence of smoking decreased from a maximum of $17.1 \%$ in June 2003 to a minimum of $10.6 \%$ in December 2011 (figure 1). The unadjusted prevalence of smoking during pregnancy decreased from 2003 to 2011 overall and for all strata examined, with a reduction of $0.39 \%$ per month in pregnancies overall (see 'Time only' models in table 1).

The smoking prevalence was consistently higher among mothers under 30 years, with a mean of $21.0 \%$ in 2003 and $15.3 \%$ in 2011 , compared with $11.0 \%$ and $6.9 \%$ in mothers aged 30 years or older. A similar pattern was observed for parity, with $18.1 \%$ and $13.4 \%$ of multiparous mothers smoking in 2003 and 2011, relative to $13.8 \%$ and $8.4 \%$ of primiparous mothers. Women in advantaged SES areas consistently demonstrated the lowest smoking prevalence (8.6\% in 2003 and $5.2 \%$ in 2011). In 2003 , the prevalence of smoking was the same $(20.5 \%)$ for women in the average and disadvantaged SES groups, but in 2011, the prevalence was down to $14.8 \%$ for the average SES group, and $16.2 \%$ for the disadvantaged SES areas.

\section{Descriptive information regarding antismoking activities}

There was substantial variability in the exposure to antismoking television advertising over the study period (figure 2). The average 3-month cumulative exposure from July 2005 to December 2011 was 1561.48 TARPs $(\mathrm{SD}=850.08)$, which is equivalent to $100 \%$ of adults in the media market being exposed to relevant advertisements an average of 16 times in the 3 months prior, or $50 \%$ of the target audience being exposed an average of 32 times.

\section{Relationship between antismoking activities and smoking prevalence}

Prior to the implementation of any of the antismoking activities evaluated here, there was a $0.34 \%$ decrease per month in the proportion of women smoking during pregnancy for the population overall (see estimates from the partially adjusted models in table 1). In all strata, this preintervention downward trend was statistically significant, with monthly decreases ranging from $0.16 \%$ to $0.86 \%$. None of the policies or population-wide programmes were associated with a significant change in the trend for the pregnant population overall. Among some of the strata examined, however, there were significant changes associated with the $50 \%$ smoking ban (combined with graphic warnings and the $75 \%$ ban), increased tobacco tax and the advertising campaign targeting pregnant women. Following the $50 \%$ ban, the decline in smoking prevalence slowed among primiparous women and those in the advantaged SES tertiles, while it was augmented in multiparous women. The tobacco tax increase was associated with a greater decline in smoking among primiparous women and women in the disadvantaged and advantaged SES tertiles, while it was associated with a lower rate of decline in smoking prevalence among multiparous women. The advertising campaign targeting pregnant women was associated with a greater rate of decline in smoking among multiparous women, and a lower rate of decline among primiparous women and women in the disadvantaged SES tertile. There was no trend change associated with the extension to a total ban on smoking in enclosed areas of licensed premises in any of the strata examined, nor any change associated with mass media.

As can be seen from the fully adjusted models (table 1), there was no significant trend in the prevalence of smoking during pregnancy between January 2003 and July 2004, when the Baby Bonus was introduced. The Baby Bonus itself was not associated with a significant change in the trend, except for an augmentation of the decline in primiparous women (RR $0.98,95 \% \mathrm{CI}$ 0.97 to 0.99 ). Other than changing the estimates of pre-existing trend in smoking, adjusting for the Baby Bonus resulted in only two meaningful changes from the unadjusted model: the augmentation of the decline previously associated with the $50 \%$ smoking ban among multiparous women was no longer statistically significant, and the $50 \%$ smoking ban was associated with a significantly lower rate of decline among women in the disadvantaged SES tertile, when previously no significant effect was observed in this group. As with the partially adjusted models, the fully adjusted models found none of the antismoking activities to be associated with a significant change in the trend for pregnancies overall. Strata-specific findings included the 50\% smoking ban being associated with a reduced rate of decline in smoking prevalence among primiparous women and those in the disadvantaged and advantaged SES tertiles, with changes in the slope ranging from $0.59 \%$ to $1.55 \%$. The increase in tobacco tax was associated with an enhancement of the downward trend $(0.9 \%$ to $2.36 \%)$ in smoking among primiparous women and women in the disadvantaged and advantaged SES tertiles, while it was associated with a $1.07 \%$ reduction in the downward trend among multiparous women. The advertising campaign targeting pregnant women was associated with a $1.36 \%$ enhancement in the downward trend for multiparous women, and a $1.77 \%$ $3.22 \%$ reduction in the downward trend among primiparous women and women in the disadvantaged SES tertile.

\section{DISCUSSION}

This study confirms the significant decline in the prevalence of smoking during pregnancy in NSW between 2003 and 2011. The partially adjusted models indicated that this downward trend existed prior to the implementation of the antismoking initiatives evaluated in this study, and that none of these initiatives were associated with a significant change in smoking prevalence for pregnancies overall. Together, these findings suggest 

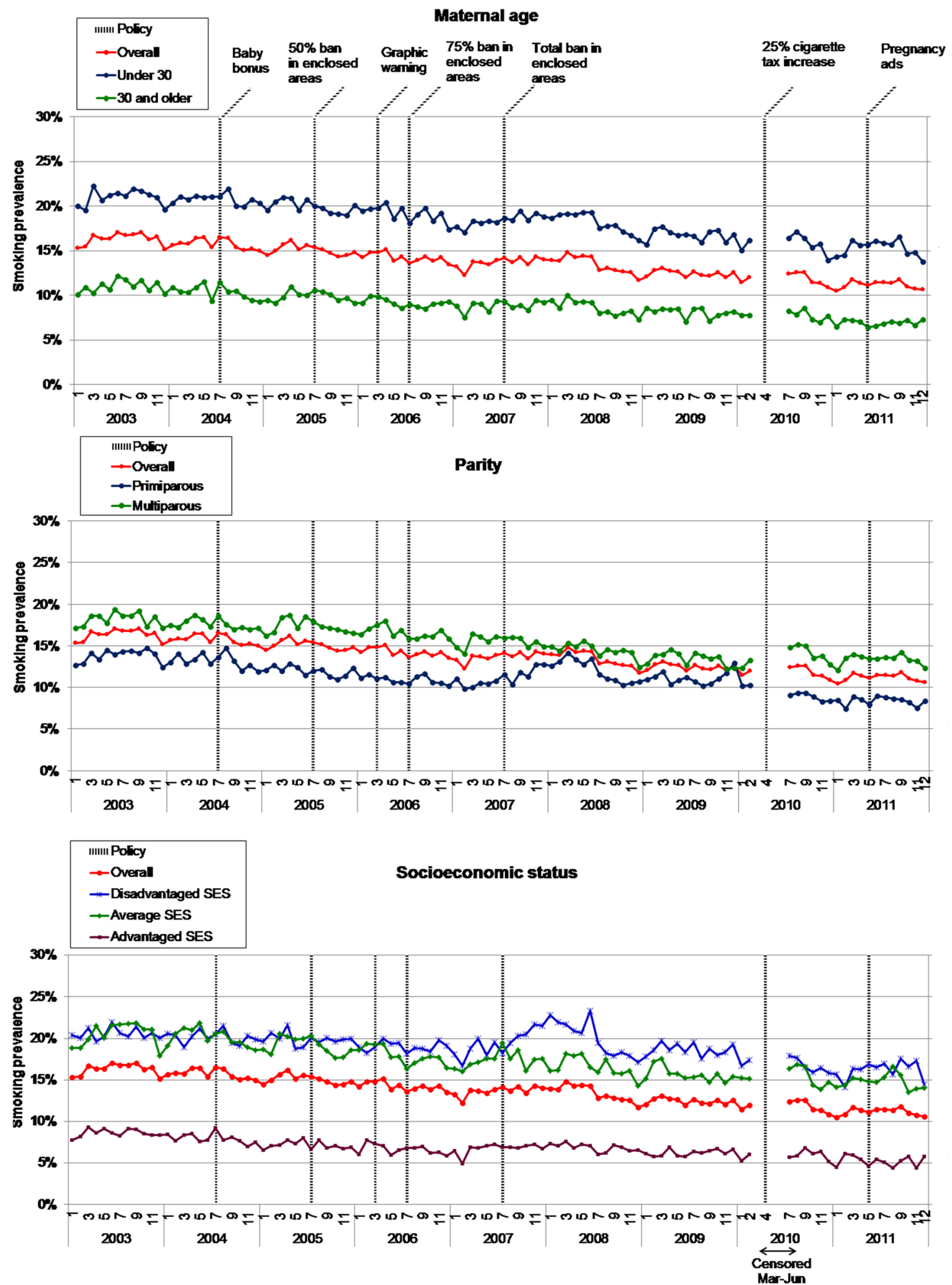

Figure 1 Monthly prevalence of smoking during pregnancy in New South Wales, 2003-2011, stratified by maternal age, parity and socioeconomic status (SES).

that the overall decline in smoking during pregnancy in 2003 to 2011 was not directly driven by the antismoking activities evaluated here. The same conclusion can be drawn from models adjusting for the Baby Bonus, which indicated that the Baby Bonus also did not contribute to the decline in smoking (except among primiparous women). That the pre-existing downward trend was not statistically significant in the fully adjusted models is likely to be an artefact of truncating the time series at July 2004, rather than at July 2005 (the implementation of the first evaluated antismoking activity). Significant changes associated with the 50\% smoking ban (in combination with graphic warnings and the $75 \%$ smoking ban), increased tobacco tax and the advertising campaign targeting pregnant women emerged in certain strata. 


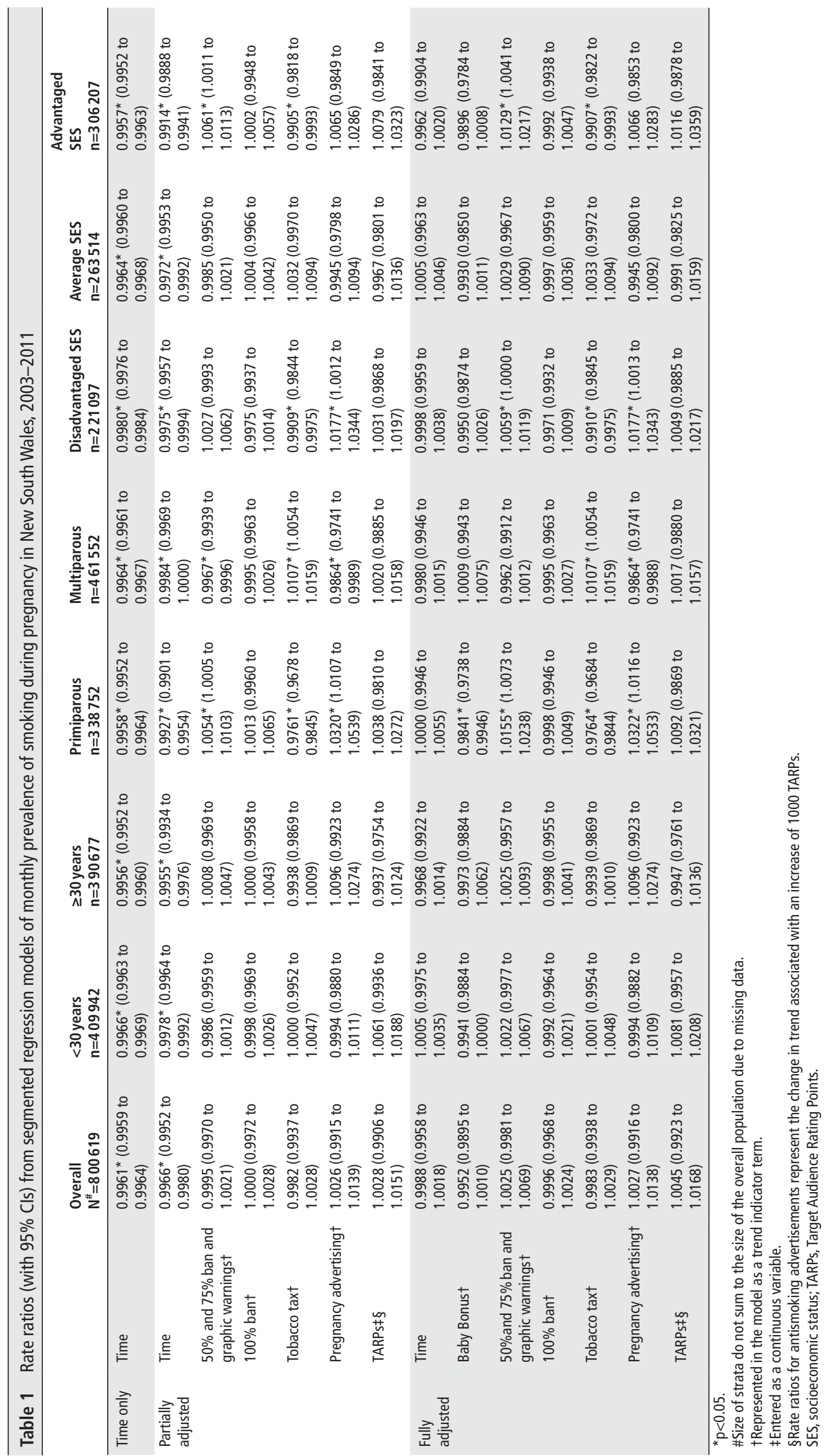




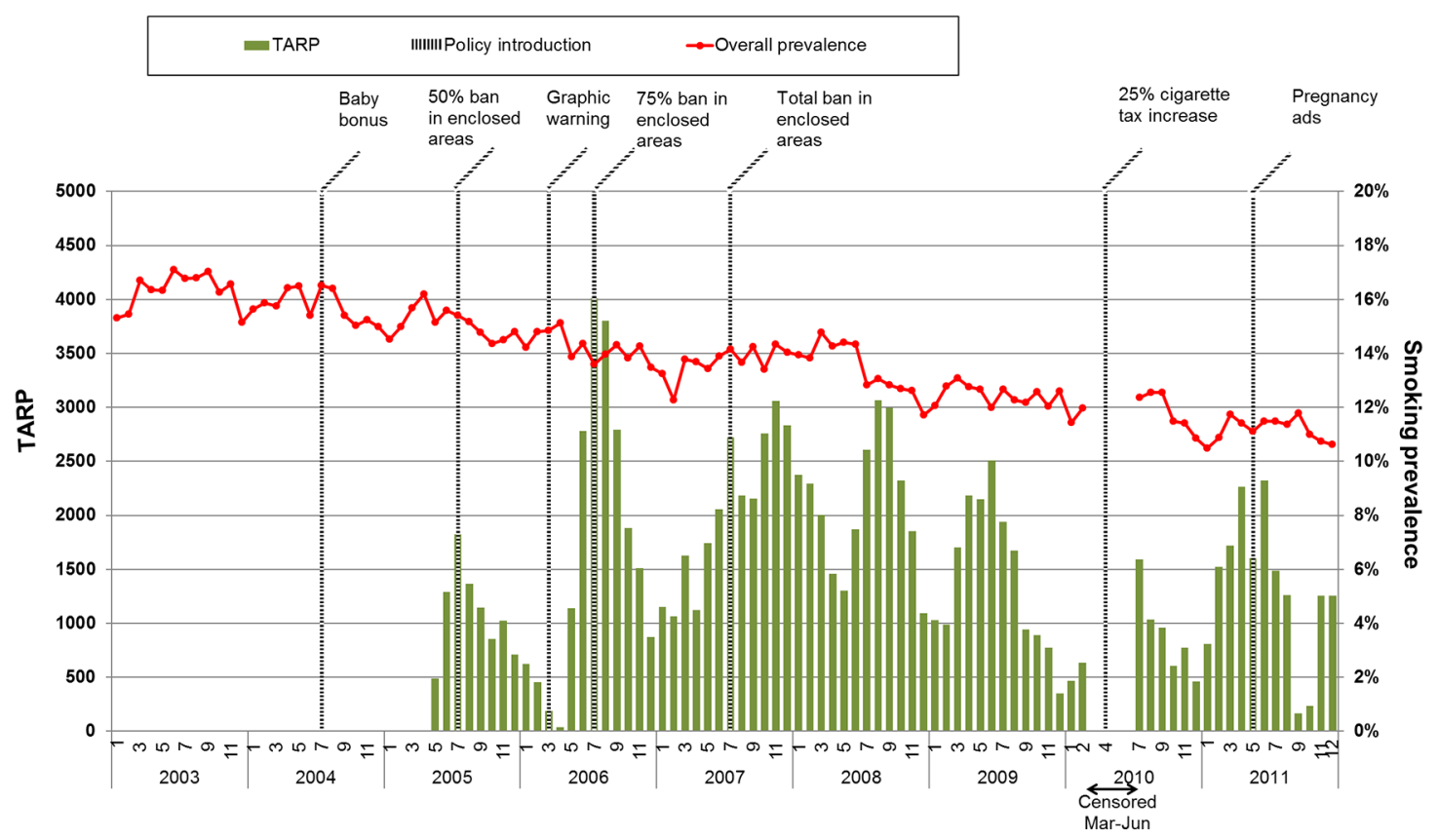

Figure 2 Exposure to population-wide antismoking measures and prevalence of smoking during pregnancy in New South Wales, 2003 to 2011. TARP, Target Audience Rating Point.

Of the antismoking activities evaluated here, prior good quality evidence existed only for increased tobacco tax and graphic warnings. Both policies were associated with increased quitting during pregnancy ${ }^{12}{ }^{15}$; increased tax was not associated with a change in smoking in the 3 months before pregnancy ${ }^{12}$; while the impact of graphic warnings on prepregnancy smoking was not evaluated. This evidence suggests that while rising tobacco taxes, and potentially other antismoking activities, may increase quitting during pregnancy, they may not be sufficient to promote quitting prior to conception, which is required for a reduction in prevalence of smoking during pregnancy to be observed. This would explain the null findings in the current study, which measured smoking at any time during pregnancy. Such a conclusion would be consistent with evidence that motivation to quit smoking is higher during pregnancy. ${ }^{36}$ This hypothesis is worthy of further exploration as it may indicate a need for programmes to specifically target women who are planning a pregnancy and/ or of childbearing age.

Indoor smoking bans in the USA, Italy and Ireland have been evaluated, finding improvements in during-pregnancy quitting, ${ }^{12}{ }^{37}$ but mixed results for any smoking during pregnancy. ${ }^{2} 3839$ Not only were the existing trend and/or other programmes not taken into account in all except one of these studies, ${ }^{12}$ but the restrictions evaluated were more extensive than those tested here, applying to smoking in workplaces and/ or restaurants and bars. As the bans evaluated here represented an extension to bans that were already in place for enclosed workplaces, shopping centres, restaurants, cafes and the dining areas of licensed indoor areas, and the impact of indoor smoking laws is smaller when some restrictions are already in place, ${ }^{40}$ the existing data are not applicable to the Australian context. Antismoking advertising has not previously been assessed for its impact on smoking during pregnancy, and the results from the current evaluation should be interpreted with caution given the absence of data on mass media exposure prior to April 2005.

Significant changes in the trend in certain strata following the $50 \%$ smoking ban (in combination with graphic warnings and the $75 \%$ smoking ban), and increased tobacco tax, are perplexing. Variation in maternal responsiveness to smoking bans of this type and graphic warnings has not been examined, so it is not known whether the dampening of the downward trend among primiparous women and those in the disadvantaged and advantaged SES tertiles represent genuine responses to these antismoking activities. Nevertheless, it is reassuring that the changes in the trend associated with the $50 \%$ ban are small in magnitude, with the greatest increase being less than $2 \%$.

Although potential variation in the impact of increased tax according to age, parity and SES has been examined previously, ${ }^{14}{ }^{18}$ findings have been inconsistent. The observed association between increased tax and a decline in smoking among women in the disadvantaged SES tertile is plausible given that low-income smokers have been found to be more price responsive than other groups. ${ }^{7}$ The divergent findings regarding the impact of tobacco tax among primiparous and multiparous women, however, are less intuitive. One potential explanation is that decreased affordability of cigarettes resulted in a greater desire to quit, and this increased saliency may have influenced women's disclosure of smoking during pregnancy. It could have resulted in reduced disclosure among primiparous women who may be more fearful of stigmatisation, while it may have increased disclosure among multiparous women, who are likely to have better understanding of the risks of smoking during pregnancy due to prior experience.

There is an important limitation to this study: there may have been other changes in the environment during the study period that contributed to changes in prevalence of smoking during pregnancy, perhaps to a different extent in different strata. We were not able to account for this by including a geographical control because most of the evaluated antismoking activities were implemented nationally. We controlled for the possibility that the Baby Bonus might influence smoking by changing the demographic composition of the pregnant population, but it is possible that other unmeasured confounders masked a relationship between the antismoking activities and smoking prevalence. In 2003, a government and industry working group agreed that pubs and clubs would voluntarily provide at least 
one smoke-free bar and a $1.5 \mathrm{~m}$ smoke-free zone around bars. ${ }^{41}$ Plain packaging was not introduced until 2012, but government support for the policy was announced in April 2010 followed by much media and community debate. While it is possible that changes in the smoking cessation support provided in antenatal care during the study period would have led to greater smoking cessation during pregnancy, quitting after conception would not have affected smoking as it was measured in the current study.

In conclusion, this study found that the decline in the prevalence of smoking during pregnancy in NSW between 2003 and 2011 was not significantly related to any of the evaluated antismoking activities that were previously demonstrated to be effective in the general population, or associated with a specific campaign targeting smoking in pregnancy. It remains possible, however, that these antismoking activities have indirectly impacted on the prevalence of maternal smoking, perhaps through gradual changes in public sentiment. ${ }^{5}$ In order to make improvements in maternal smoking that are more than incremental, it would be worthwhile evaluating antismoking activities that target pregnancy specifically. While the pregnancy-targeted advertising campaign evaluated here was not associated with a change in smoking prevalence, this campaign had limited reach. Further targeted advertising in 2012 to 2014, which was found to have greater media buy-in, ${ }^{34}$ should be evaluated for its impact on the prevalence of smoking during pregnancy.

\section{What this paper adds}

- World-leading population-wide activities and policies implemented in Australia between 2003 and 2011, including mass media, graphic health warnings on cigarette packaging, increase in tobacco taxes and the extension of the ban of smoking in enclosed public places to include licensed premises, have demonstrated effectiveness in the general population. Increased tobacco tax and graphic warnings have been demonstrated to increase smoking cessation during pregnancy.

- It is not known whether these antismoking initiatives influence the number of women who are current smokers when they become pregnant.

- This population-based study found that the decline in the prevalence of smoking during pregnancy in NSW between 2003 and 2011 was not a direct result of the antismoking activities evaluated.

Acknowledgements The authors would like to thank the NSW Ministry of Health for providing data and the Centre for Health Record Linkage for performing the linkage. We also thank the Cancer Institute NSW for providing TARPs data and advice regarding their interpretation.

Contributors All authors contributed to the study. The study was conceived by $\mathrm{AH}$, and designed by AH, DTT and AKC. The analysis was executed by DTT. KE, DP and LJ contributed to the design. AH drafted the manuscript, with input from all authors.

Funding This research was supported by an Australian National Health and Medical Research Council Project Grant (\#1028543) and AH is supported by a National Heart Foundation Future Leader Fellowship (\#100411). The funders had no involvement in the study design; the collection, analysis or interpretation of the data; in the writing of the report or the decision to submit the report for publication.

Competing interests All authors have completed the ICMJE uniform disclosure form and declare: all authors had financial support from the National Health and Medical Research Council for the submitted work; $\mathrm{AH}$ also received financial support from the National Heart Foundation; no financial relationships with any organisations that might have an interest in the submitted work in the previous three years; no other relationships or activities that could appear to have influenced the submitted work.

Ethics approval NSW Population and Health Services Research Ethics Committee. Provenance and peer review Not commissioned; externally peer reviewed.

Data sharing statement The data sets were constructed with the permission of each of the source data custodians and with specific ethical approvals. Authors do not have permission to share patient-level data because of the highly confidential nature of the data. Permission to access to the data is restricted to researchers named and approved by relevant human research ethics committees.

Open access This is an open access article distributed in accordance with the Creative Commons Attribution Non Commercial (CC BY-NC 4.0) license, which permits others to distribute, remix, adapt, build upon this work non-commercially, and license their derivative works on different terms, provided the original work is properly cited and the use is non-commercial. See: http://creativecommons.org/ licenses/by-nc/4.0/

(c) Article author(s) (or their employer(s) unless otherwise stated in the text of the article) 2018. All rights reserved. No commercial use is permitted unless otherwise expressly granted.

\section{REFERENCES}

1 Australian Institute of Health and Welfare. Australia's mothers and babies 2014 - in brief. Perinatal statistics series no 32. Canberra: AlHW, 2016.

2 Laws P, Sullivan E. Australia's mothers and babies 2003. Perinatal Statistics Series. Sydney: AlHW National Perinatal Statistics Unit, 2005.

3 Australian Government Department of Health. National tobacco campaign - More targeted approach - Phase 2 pregnancy component. Quantitative campaign effectiveness research - Final report, 2012.

4 Australian Government Department of Health. National tobacco Campaign - More targeted approach \& break the Chain. Campaign evaluation, 2014.

5 Mohsin M, Bauman AE, Forero R, et al. Socioeconomic correlates and trends in smoking in pregnancy in New South Wales, Australia. J Epidemio/ Community Health 2011;65:727-32

6 Scollo M, Younie S, Wakefield M, et al. Impact of tobacco tax reforms on tobacco prices and tobacco use in Australia. Tob Control 2003;12(Suppl 2):59ii-66.

7 Siahpush M, Wakefield MA, Spittal MJ, et al. Taxation reduces social disparities in adult smoking prevalence. Am J Prev Med 2009;36:285-91.

8 Wakefield MA, Coomber K, Durkin SJ, et al. Time series analysis of the impact of tobacco control policies on smoking prevalence among australian adults, 2001-2011. Bull World Health Organ 2014;92:413-22.

9 Wakefield MA, Durkin S, Spittal MJ, et al. Impact of tobacco control policies and mass media campaigns on monthly adult smoking prevalence. Am J Public Health 2008;98:1443-50.

10 Young JM, Stacey I, Dobbins TA, et al. Association between tobacco plain packaging and Quitline calls: a population-based, interrupted time-series analysis. Med J Aust 2014;200:29-32.

11 Nagelhout GE, Willemsen MC, de Vries H, et al. The population impact of smoke-free workplace and hospitality industry legislation on smoking behaviour. findings from a national population survey. Addiction 2011;106:816-23.

12 Adams EK, Markowitz S, Kannan V, et al. Reducing prenatal smoking: the role of state policies. Am J Prev Med 2012;43:34-40.

13 Bradford WD. Pregnancy and the demand for cigarettes. Am Econ Rev 2003;93:1752-63.

14 Colman G, Grossman M, Joyce T, et al. The effect of cigarette excise Taxes on smoking before, during and after pregnancy. J Health Econ 2003;22:1053-72.

15 Harris JE, Balsa Al, Triunfo P, et al. Tobacco control campaign in Uruguay: impact on smoking cessation during pregnancy and birth weight. $J$ Health Econ 2015;42:186-96

16 Levy DE, Meara E. The effect of the 1998 Master Settlement Agreement on prenatal smoking. J Health Econ 2006;25:276-94.

17 Lien D, Evans W. Estimating the impact of large cigarette tax hikes: the case of maternal smoking and infant birth weight. J Hum Resour 2004;40:373-92.

18 Ringel JS, Evans WN. Cigarette Taxes and smoking during pregnancy. Am J Public Health 2001;91:1851-6.

19 Bentley JP, Ford JB, Taylor LK, et al. Investigating linkage rates among probabilistically linked birth and hospitalization records. BMC Med Res Methodol 2012;12:149.

20 Centre for Health Record Linkage. Quality Assurance 2011. http://www.cherel.org.au/ quality-assurance (accessed 2 Jul 2014).

21 Tran DT, Roberts CL, Havard A, et al. Linking birth records to hospital admission records enhances the identification of women who smoke during pregnancy. Aust N Z J Public Health 2014;38:258-64.

22 Colvin L, Slack-Smith L, Stanley FJ, et al. Pharmacovigilance in pregnancy using population-based linked datasets. Pharmacoepidemiol Drug Saf 2009;18:211-25.

23 Dunlop S, Cotter T, Perez D, et al. Televised antismoking advertising: effects of level and duration of exposure. Am J Public Health 2013;103:e66-73. 
24 Wakefield MA, Spittal MJ, Yong HH, et al. Effects of mass media campaign exposure intensity and durability on quit attempts in a population-based cohort study. Health Educ Res 2011;26:988-97.

25 Scollo M, Winstanley M. Tobacco in Australia: facts and issues. Melbourne: Cancer Council Victoria, 2015.

26 Australian Government Department of Health. National tobacco campaign - More targeted approach: pregnant smoker survey, 2011. http://www.quitnow.gov.au/ internet/quitnow/publishing.nsf/Content/ntc-pregeval-execsumm (accessed 6 Dec 2016).

27 McCullagh P, Nelder J. Generalized linear models. 2nd ed. London: Chapman and Hall, 1989.

28 Hilbe J. Negative binomial regression. 2nd ed. Cambridge: Cambridge University Press, 2011.

29 Davis RA, Wu R. A negative binomial model for time series of counts. Biometrika 2009:96:735-49.

30 Kemp A, Preen D, Sanfilippo F, et al. Evaluating pharmaceutical policy impacts using interrupted time series analysis: an australian case study. Int J Public Health 2011;3:229-41.

31 Penfold RB, Zhang F. Use of interrupted time series analysis in evaluating health care quality improvements. Acad Pediatr 2013;13:S38-44.

32 Australian Bureau of Statistics. Information paper: Census of Population and Housing 2 Socio2Economic Indexes for Areas, Australia, 2001 Canberra: Australian Bureau of Statistics; 2003. http://www.abs.gov.au/ausstats/abs@.nsf/allprimarymainfeatures/ 09D68973F50B8258CA2573F0000DA181?opendocument (accessed 15 Mar 2011).
33 Australian Bureau of Statistics. Information paper: An introduction to Socio2Economic Indexes for Areas (SEIFA. Canberra: Australian Bureau of Statistics, 2008. http://www.abs.gov.au/ausstats/abs@.nsf/mf/2039.0/ (accessed 15 Mar 2011).

34 Lain SJ, Ford JB, Raynes-Greenow CH, et al. The impact of the Baby Bonus payment in New South Wales: who is having "one for the country"? Med J Aust 2009;190:238-41.

35 SAS version 9.3 [program]. Cary (North Carolina): SAS Institute, 2011.

36 DiClemente $C$, Dolan-Mullen P, Winsdsor R, et al. The process of pregnancy smoking cessation: implications for interventions. Tob Control 2000;9(Suppl 3):iii16-21.

37 Charrier L, Serafini P, Giordano L, et al. Smoking habits in italian pregnant women: any changes after the ban? J Public Health Policy 2010;31:51-8.

38 Kabir Z, Clarke V, Conroy R, et al. Low birthweight and preterm birth rates 1 year before and after the irish workplace smoking ban. BJOG 2009;116:1782-7.

39 Nguyen KH, Wright RJ, Sorensen G, et al. Association between local indoor smoking ordinances in Massachusetts and cigarette smoking during pregnancy: a multilevel analysis. Tob Control 2013;22:184-9.

40 Levy DT, Friend K, Polishchuk E, et al. Effect of clean indoor air laws on smokers: the clean air module of the SimSmoke computer simulation model. Tob Control 2001;10:345-51.

41 Bryan-Jones K, Chapman S. Political dynamics promoting the incremental regulation of secondhand smoke: a case study of New South Wales, Australia. BMC Public Health 2006;6:192. 